\title{
Chiral phosphine Lewis bases in catalytic, asymmetric aza-Morita-Baylis-Hillman reaction*
}

\author{
Min Shi ${ }^{\ddagger}$ and Lian-Hui Chen \\ State Key Laboratory of Organometallic Chemistry, Shanghai Institute of Organic \\ Chemistry, Chinese Academy of Sciences, 354 Fenglin Lu, Shanghai 200032, \\ China
}

\begin{abstract}
In the aza-Morita-Baylis-Hillman reaction of $N$-sulfonated imines with methyl vinyl ketone (MVK) promoted by chiral phosphine Lewis base: $(R)$-2'-diphenylphosphanyl[1,1']binaphthalenyl-2-ol (LB1) (10 mol \%), the aza-Morita-Baylis-Hillman adducts were obtained in good yields with high ee (70-94\% ee) at $-30{ }^{\circ} \mathrm{C}$ in THF. The scope and limitations of this reaction have been disclosed.
\end{abstract}

Keywords: aza-Baylis-Hillman; $N$-sulfonated imines; chiral phosphine Lewis bases; Baylis-Hillman reaction; methyl vinyl ketone.

\section{INTRODUCTION}

Great progress has been made in the execution of the Morita-Baylis-Hillman reaction [1] since the seminal report in 1972 [2] described the reaction of acetaldehyde with ethyl acrylate and acrylonitrile in the presence of catalytic amounts of 1,4-diazabicyclo[2,2,2]octane (DABCO). Recent advances include a catalytic asymmetric version of the reaction [3], but limited to specialized $\alpha, \beta$-unsaturated ketones or acrylates such as ethyl vinyl ketone (71 \% ee) [3a], 2-cyclohexen-1-one (96\% ee) [3b], or 1,1,1,3,3,3-hexafluoroisopropyl acrylate (99\% ee) [3c]. Morita-Baylis-Hillman reactions involving simple Michael acceptors such as methyl vinyl ketone (MVK) or methyl acrylate have hitherto been characterized by poor enantioselectivity, thus offering a challenging and potentially fruitful area of investigation to broaden the scope of this general class of reactions. During our ongoing investigations of the aza-Morita-Baylis-Hillman reaction [4], we disclosed that the aza-Morita-Baylis-Hillman reactions of $\mathrm{N}$-sulfonated imines (ArCH=NTs) [5] with $\mathrm{MVK}$ were promoted in the presence of catalytic amounts of Lewis bases such as triphenylphosphine $\left(\mathrm{PPh}_{3}\right)$ or DABCO to exclusively give the normal aza-Morita-Baylis-Hillman adducts in good yields for many $\mathrm{N}$-sulfonated imines under mild conditions because the $N$-sulfonated imino group has high reactivity toward nucleophilic attack, even when the phenyl ring bears electron-donating groups [4a]. We then sought a suitable chiral Lewis base for a catalytic, asymmetric version of this reaction. Previously, we reported an unprecedented catalytic, asymmetric aza-Morita-Baylis-Hillman reaction of $N$-sulfonated imines with MVK utilizing a nitrogen Lewis base $\{4$-(3-ethyl-4-oxa-1-azatricyclo[4,4,0,0 3,8 dec-5-yl)-quinolin-6-ol: TQO [3c] $\}$ to achieve $>90 \%$ ee in good yields [4b]. This is the first case in which high ee can be realized using the simple Michael acceptor MVK. The structure of this nitrogen Lewis base plays a very important role in this reaction for achieving high ee. Currently, the exploration of a novel and highly efficient chiral Lewis base

\footnotetext{
*Paper based on a presentation at the $7^{\text {th }}$ IUPAC International Conference on Heteroatom Chemistry (ICHAC-7), Shanghai, China, 21-25 August 2004. Other presentations are published in this issue, pp. 1985-2132.

¥Corresponding author: E-mail: mshi@pub.sioc.ac.cn; Fax: 86-21-64166128
} 
for catalytic, asymmetric Morita-Baylis-Hillman reaction is a very attractive and competitive field. Herein, we wish to report the catalytic, asymmetric aza-Morita-Baylis-Hillman reaction using a chiral phosphine Lewis base in which high enantioselectivities ( $>90 \%$ ee) can also be realized.

\section{RESULTS AND DISCUSSION}

We selected $(R)-2$ '-diphenylphosphanyl-[1,1']binaphthalenyl-2-ol (LB1) as a chiral Lewis base for this reaction because it has a phenolic OH group like Lewis base TQO [3c]. We first used MVK as the Michael acceptor for the aza-Morita-Baylis-Hillman reaction with $N$-sulfonated imines (Scheme 1). In THF, at $-30^{\circ} \mathrm{C}$, good to high enantioselectivities (76 91\% ee) were achieved with $S$ configuration [4b] (Table 1). In general, for $N$-sulfonated imines having electron-donating groups on the phenyl ring, the reaction rate was slightly retarded and the corresponding aza-Morita-Baylis-Hillman adducts 1 were obtained in lower yields (41 62\%) with 76 83\% ee under the same conditions (Table 1, entries 1-3). It was suspected that moisture-induced decomposition of $N$-sulfonated imine may have intervened during prolonged reaction times at low temperature. This was verified, and yields of $\mathbf{1}$ were correspondingly improved by adding $4 \AA$ molecular sieve ( $100 \mathrm{mg}$ for $0.5 \mathrm{mmol}$ of substrate) to the reaction medium. Reactions thus conducted under strictly anhydrous conditions showed marked improvement in yields of 1 (Table 1, entries 1-3, 5, 7-10), with little or no adverse effect on ee results. Only in some cases, the ee of 1 dropped $\sim 2-7 \%$. Values in parentheses are the results obtained in the presence of $4 \AA$ molecular sieve in Table 1.

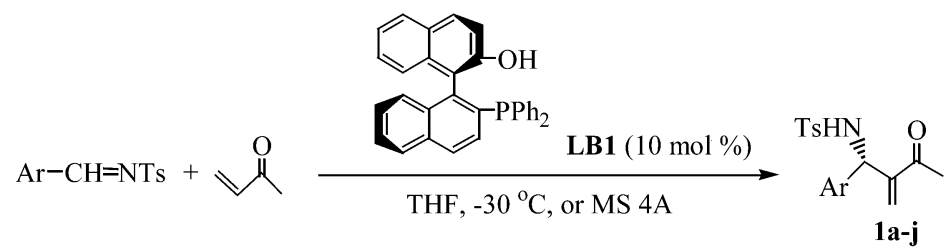

\section{Scheme 1}

Table 1 The aza-Baylis-Hillmann reactions of $N$-sulfonated imines (1.0 equiv) with MVK in the presence of chiral Lewis base $(10 \mathrm{~mol} \%)$.

\begin{tabular}{cllllc}
\hline Entry & \multicolumn{1}{c}{$\mathrm{Ar}$} & Time/h & \multicolumn{1}{c}{ Yield/\% } & ee/\% & \multicolumn{2}{c}{$\begin{array}{c}\text { Absolute } \\
\text { configuration }\end{array}$} \\
\hline 1 & $\mathrm{C}_{6} \mathrm{H}_{5}$ & $24(36)^{\mathrm{c}}$ & $\mathbf{1 a}, 49(83)^{\mathrm{c}}$ & $83(83)^{\mathrm{c}}$ & $S$ \\
2 & $p-\mathrm{MeC}_{6} \mathrm{H}_{4}$ & $24(36)$ & $\mathbf{1 b}, 53(82)$ & $80(81)$ & $S$ \\
3 & $p-\mathrm{EtC}_{6} \mathrm{H}_{4}$ & $36(36)$ & $\mathbf{1 c}, 62(84)$ & $76(79)$ & $S$ \\
4 & $p-\mathrm{FC}_{6} \mathrm{H}_{4}$ & 18 & $\mathbf{1 d}, 84$ & 81 & $S$ \\
5 & $p-\mathrm{ClC}_{6} \mathrm{H}_{4}$ & $24(24)$ & $\mathbf{1 e}, 72(90)$ & $94(87)$ & $S$ \\
6 & $p-\mathrm{BrC}_{6} \mathrm{H}_{4}$ & 18 & $\mathbf{1 f}, 85$ & 83 & $S$ \\
7 & $m-\mathrm{FC}_{6} \mathrm{H}_{4}$ & $36(24)$ & $\mathbf{1 g}, 26(96)$ & $91(85)$ & $S$ \\
8 & $m-\mathrm{ClC}_{6} \mathrm{H}_{4}$ & $18(24)$ & $\mathbf{1 h}, 62(88)$ & $88(88)$ & $S$ \\
9 & $p-\mathrm{NO}_{2} \mathrm{C}_{6} \mathrm{H}_{4}$ & $12(24)$ & $\mathbf{1 i}, 60(86)$ & $94(92)$ & $S$ \\
10 & $m-\mathrm{NO}_{2} \mathrm{C}_{6} \mathrm{H}_{4}$ & $12(24)$ & $\mathbf{1 j}, 54(91)$ & $90(88)$ & $S$ \\
\hline
\end{tabular}

assolated yield.

betermined by chiral HPLC.

${ }^{c}$ Values in parentheses are the results in the presence of MS $4 \AA$ (100 mg). 
It should be emphasized here that the phenolic hydroxy group ( $\mathrm{Ar}-\mathrm{OH})$ on the naphthyl ring is crucial for this reaction because this reaction becomes sluggish and gives the product 1e in $13 \%$ yield with only $20 \%$ ee ( $R$ configuration) using $O$-methylated ligand (MOP) LB2 as a chiral Lewis base [6a] and in $22 \%$ yield with $17 \%$ ee ( $R$ configuration) using (2'-ethyl-[1,1']binaphthalenyl-2yl)diphenylphosphane LB3 as a chiral Lewis base [6a] under the same conditions (Scheme 2). The BINAP LB4 shows no catalytic activity for this reaction. The $(R)-2$ '-diphenylphosphanyl-[1,1']binaphthalenyl-2-thiol LB5 having a thiophenolic group on the naphthyl ring [6b,c] and the [2,3-bis-(2diphenylphosphanyl-phenyl)-4-hydroxymethyl-cyclobutyl]methanol LB6 [6d] having two aliphatic hydroxy groups show low catalytic activities under the same conditions. These results suggest that the acidity of the hydroxy group plays a very important role for chiral Lewis base LB1 to be effective in the aza-Morita-Baylis-Hillman reaction. Other chiral ferrocene phosphine ligands LB7 and LB8 [6e,f] also have low catalytic activities for this reaction under the same conditions. Thus, the structure of phosphine Lewis base plays a significant role in this reaction (Scheme 2). Only $(R)-2$ '-diphenylphosphanyl[1,1']binaphthalenyl-2-ol LB1 having a phenolic hydroxy group can effectively catalyze this asymmetric aza-Morita-Baylis-Hillman reaction to give the products in good yields and ee.

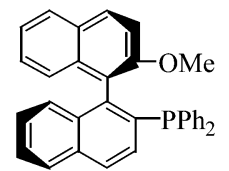

LB2

Yield: $13 \%$, ee: $20 \%, R$

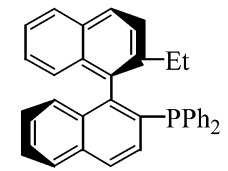

LB3<smiles>c1ccc2c(-c3cccc4ccccc34)cccc2c1</smiles>

LB4<smiles>Sc1ccc2ccccc2c1-c1c(-c2ccccc2)ccc2ccccc12</smiles>

LB5

Yield: $17 \%$, ee: $22 \%, R$

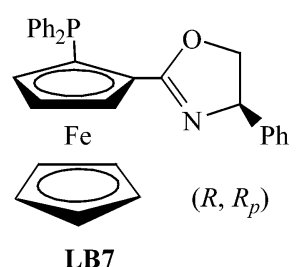

Yield: $45 \%$, ee: $65 \%, S$

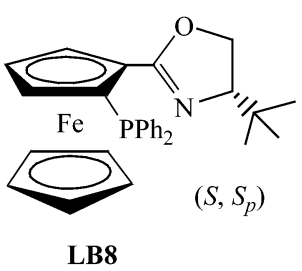

Yield: $44 \%$, ee: $38 \%, R$

Yield: $78 \%$, ee: $18 \%, S$

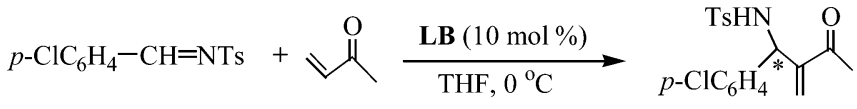

\section{Scheme 2}

The scope and limitations of this catalytic, asymmetric reaction for a variety of Michael acceptors such as ethyl vinyl ketone, acrolein, and phenyl acrylate with $\mathrm{N}$-(4-chlorobenzylidene)-4-methylbenzenesulfonamide under the corresponding optimized conditions have been shown in Scheme 3. 


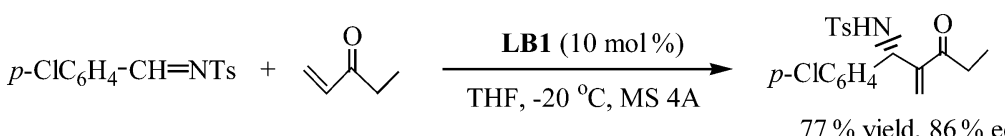

$$
\begin{aligned}
& p-\mathrm{ClC}_{6} \mathrm{H}_{4}-\mathrm{CH}=\mathrm{NTs}+\stackrel{\mathrm{O}}{\mathrm{H}}_{\mathrm{H}} \\
& \underset{\mathrm{THF}, 20^{\circ} \mathrm{C}}{\stackrel{\text { LB1 }(10 \mathrm{~mol} \%)}{\longrightarrow}} \\
& p-\mathrm{ClC}_{6} \mathrm{H}_{4} \\
& 91 \% \text { yield, } 83 \% \text { ee } \\
& p-\mathrm{ClC}_{6} \mathrm{H}_{4}-\mathrm{CH}=\mathrm{NTs}+\stackrel{\mathrm{O}}{\mathrm{O}}_{\mathrm{OPh}} \\
& \underset{\mathrm{CH}_{2} \mathrm{Cl}_{2}, 40^{\circ} \mathrm{C}}{\stackrel{\text { LB1 }}{\stackrel{\mathrm{O}}{\mathrm{C}} \mathrm{mol} \%)}} \\
& p-\mathrm{ClC}_{6} \mathrm{H}_{4} \mathrm{OPh}
\end{aligned}
$$

\section{Scheme 3}

In Fig. 1, we briefly gave a mechanistic speculation on the chiral Lewis base LB1 [4a]. We believe that LB1 acted as a bifunctional chiral catalyst in this reaction [7]. The phosphine atom acted as a Lewis base (LB) to initiate the Morita-Baylis-Hillman reaction and the phenolic OH group (Brønsted acid: BA) acted as a Lewis acid through hydrogen bonding to stabilize the reaction intermediate (Fig. 1). Thus, this is a LBBA (Lewis base and Brønsted acid) bifunctional catalyst system. The transition state of this reaction for the outcome of stereochemistry has been shown in previous literature [4a].

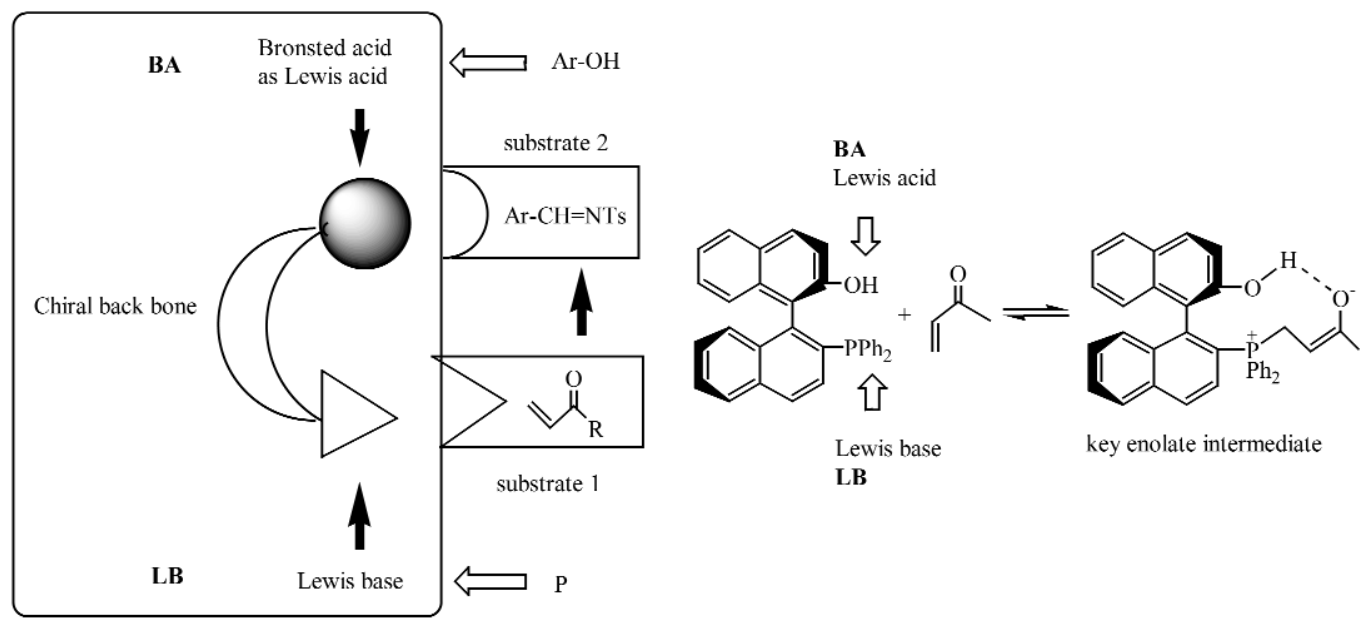

chiral phosphine Lewis base catalyst: LBBA bifunctional catalytic system.

Fig. 1 The plausible reaction mechanism.

The significant advantage in this chiral phosphine Lewis base system is that it is "structure-tunable". In Scheme 3, we presented the synthesis of a chiral Lewis base LB9 with two perfluoroalkane long chains ("pony tail") on the 6,6'-position because the previous results on asymmetric catalysis have indicated that such a "pony tail" in chiral ligand can indeed improve the enantioselectivities under identical conditions [8]. Bromination and protection by benzyl group gave product LB9-1, which was subjected to the Heck-type coupling reaction with 3,3,4,4,5,5,6,6,7,7,8,8,8-tridecafluoro-1-octene in the presence of $\mathrm{Pd}(\mathrm{OAc})_{2}$ and $(o-\mathrm{Tol})_{3} \mathrm{P}$ ligand in dimethylformamide (DMF) at $125{ }^{\circ} \mathrm{C}$ to furnish product $\mathbf{L B 9}$-2 in good yield. Catalytic hydrogenation over $\mathrm{Pd}(\mathrm{OH})_{2} / \mathrm{C}$ in methanol gave product LB9-3 in high yield [9]. The reaction of LB9-3 with $\mathrm{Tf}_{2} \mathrm{O}$ in the presence of pyridine produced the product LB9-4. The coupling 
reaction of LB9-4 with diphenylphosphite and hydrolysis with aqueous sodium hydroxide solution in 1,4-dioxane/MeOH mixed solvent produced the compound LB9-6 in good yield. The reduction of phosphate LB9-6 by $\mathrm{HSiCl}_{3}$ and $\mathrm{Et}_{3} \mathrm{~N}$ in toluene at $120{ }^{\circ} \mathrm{C}$ afforded the chiral phosphine Lewis base $\mathbf{L B 9}$ having so-called "pony tail" was obtained in good yield (Scheme 4). The preliminary examination in THF has been performed, and the results are summarized in Table 2. For various $N$-sulfonated imines, the corresponding adducts 1 were obtained in good yields and high ee at $-20^{\circ} \mathrm{C}$ (Table 2). This finding opens a way for the design and synthesis of special chiral phosphine Lewis bases which can be used in fluorous phase and $\mathrm{scCO}_{2}$ in the future because a long perfluorinated alkyl chain, so-called "pony tail", could indeed help the catalyst in the fluorous phase and $\mathrm{scCO}_{2}$ to become more effective [10].
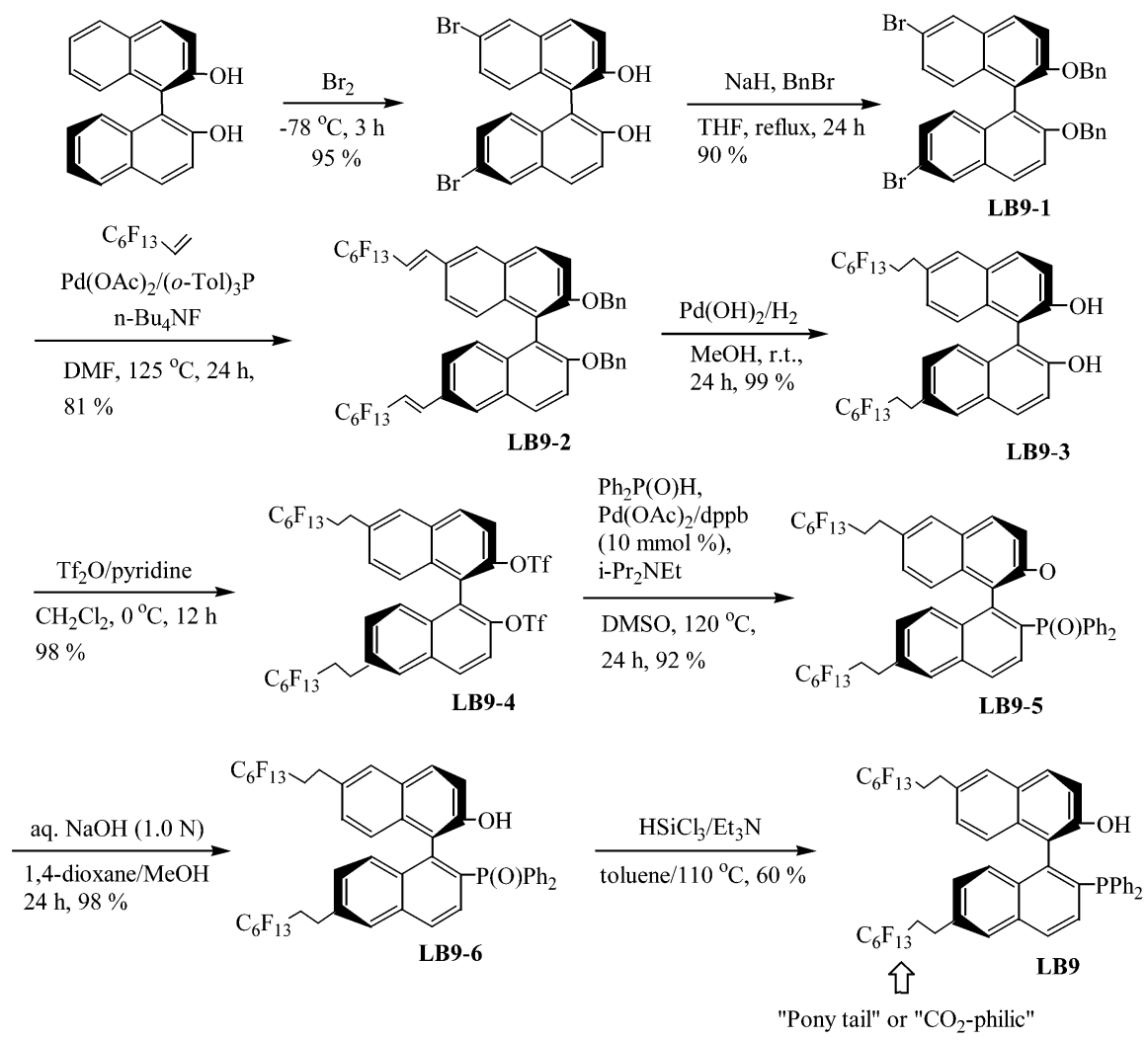

\section{Scheme 4}

Table 2 aza-Baylis-Hillmann reactions of $N$-sulfonated imines (1.0 equiv) with MVK (3.0 equiv) in the presence of chiral Lewis base LB9 (10 mol \%).

\begin{tabular}{llcccc}
\hline Entry & \multicolumn{1}{c}{$\mathrm{Ar}$} & Time/h & $\frac{\mathrm{Yield} / \%^{\mathrm{a}}}{\mathbf{1}}$ & $\mathrm{ee} / \%^{\mathrm{b}}$ & $\begin{array}{c}\text { Absolute } \\
\text { configuration }\end{array}$ \\
\hline 1 & $\mathrm{C}_{6} \mathrm{H}_{5}$ & 48 & $\mathbf{1 a}, 91$ & 71 & $S$ \\
2 & $p-\mathrm{ClC}_{6} \mathrm{H}_{4}$ & 12 & $\mathbf{1 e}, 60$ & 94 & $S$ \\
3 & $p-\mathrm{BrC}_{6} \mathrm{H}_{4}$ & 24 & $\mathbf{1 f}, 83$ & 93 & $S$ \\
4 & $p-\mathrm{FC}_{6} \mathrm{H}_{4}$ & 24 & $\mathbf{1 g}, 69$ & 92 & $S$ \\
5 & $p-\mathrm{NO}_{2} \mathrm{C}_{6} \mathrm{H}_{4}$ & 12 & $\mathbf{1 i}, 83$ & 86 & $S$ \\
6 & $m-\mathrm{NO}_{2} \mathrm{C}_{6} \mathrm{H}_{4}$ & 24 & $\mathbf{1 j}, 84$ & 95 & $S$ \\
\hline
\end{tabular}

asolated yield.

${ }^{b}$ Determined by chiral HPLC. 


\section{ACKNOWLEDGMENTS}

We thank the National Natural Science Foundation of China for financial support (20025206, 203900502, and 20272069).

\section{REFERENCES}

1. (a) E. Ciganek. Org. React. 51, 201 (1997); (b) D. Basavaiah, P. D. Rao, R. S. Hyma. Tetrahedron 52, 8001 (1996).

2. (a) A. B. Baylis and M. E. D. Hillman. Ger. Offen. 2, 155,113 (1972); Chem. Abstr. 77, 34174q (1972); M. E. D. Hillman and A. B. Baylis. U.S. Patent 3,743,669 (1973); (b) K. Morita, Z. Suzuki, H. Hirose. Bull. Chem. Soc. Jpn. 41, 2815 (1968).

3. (a) A. G. M. Barrett, A. S. Cook, A. Kamimura. Chem. Commun. 2533 (1998); (b) N. T. McDougal and S. E. Schaus. J. Am. Chem. Soc. 125, 12094 (2003); (c) Y. Iwabuchi, M. Nakatani, N. Yokoyama, S. Hatakeyama. J. Am. Chem. Soc. 121, 10219 (1999).

4. (a) M. Shi and Y.-M. Xu. Chem. Commun. 1876 (2001); (b) M. Shi and Y.-M. Xu. Angew. Chem., Int. Ed. Engl. 41, 4503 (2002).

5. B. E. Love, P. S. Raje, T. C. Williams. Synlett 493 (1994).

6. (a) Y. Uozumi, A. Tanahashi, S.-Y. Lee. Lee, T. Hayashi. J. Org. Chem. 58, 1945 (1993); (b) J. Kang, S. H. Yu, J. I. Kim, H. G. Cho. Bull. Korean Chem. Soc. 16, 439 (1995); (c) S. Gladiali, S. Medici, G. Pirri, S. Pulacchini, D. Fabbri. Can. J. Chem. 79, 670 (2001); (d) D. Zhao and K.-L. Ding. Org. Lett. 5, 1349 (2003); (e) S.-L. You, X.-L. Hou, L.-X. Dai, B.-X. Cao, J. Sun. Chem. Commun. 1933 (2000); (f) W.-P. Deng, X.-L. Hou, L.-X. Dai, X.-W. Dong. Chem. Commun. 1483 (2000).

7. Bifunctional chiral ligands: see: Y. M. A. Yamada, N. Yoshikawa, H. Sasai, M. Shibasaki. Angew. Chem., Int. Ed. Engl. 36, 1871 (1997).

8. (a) J.-W. Han and T. Hayashi. Tetrahedron: Asymmetry 13, 325 (2002); (b) Y. Tian, Q.-C. Yang, T. C. W. Mak, K.-S. Chan. Tetrahedron 58, 3951 (2002).

9. W.-P. Chen, L.-J. Xu, J.-L. Xiao. Tetrahedron Lett. 42, 4275 (2002).

10. I. T. Horvath and J. Rabai. Science 266, 72 (1994); (b) I. T. Horvath. Acc. Chem. Res. 31, 641 (1998); (c) D. P. Curran. Angew. Chem., Int. Ed. Engl. 37, 1175 (1998). 